\title{
Investigation of Surface Film Formed on Fine Mg Particles
}

\author{
Jian $\mathrm{Li}^{1}$, G.J. Kipouros ${ }^{2}$, P. Burke ${ }^{2}$ and C. Bibby ${ }^{1}$ \\ ${ }^{1}$ Materials Technology Laboratory, CANMET, 568 Booth St. Ottawa, Ontario, Canada, K1A 0G1 \\ ${ }^{2}$ Materials Engineering Programme, Faculty of Engineering, Dalhousie University, 1360 Barrington \\ Street, Halifax, Nova Scotia, Canada, B3J 2X4
}

Driven by the increased need to reduce vehicle weight in order to reduce fuel consumption, hence Green House Gas (GHG) emissions, lightweight magnesium alloys have become more attractive to the automotive sector in recent years. In the development of powder metallurgical processes for $\mathrm{Mg}$ alloys, surface oxidation of fine $\mathrm{Mg}$ particles becomes inevitable due to its high reactivity. The thin surface films on these particles, due to the exposure to air in many circumstances, can act as a significant barrier to powder bonding by diffusion during sintering. It is thus essential to characterize not only the thickness but the nature of this surface film [1].

A pure $\mathrm{Mg}$ powder sample exposed in air for 7 weeks was used in this study. The particle size ranges from $1-50 \mu \mathrm{m}$ in diameter. Direct TEM observation by sprinkling Mg particles directly onto a carbon-coated TEM grid yields little success due to limited electron beam penetration depth. In addition, the complex geometry prevented reliable EDS composition and electron diffraction analysis.

Techniques of using Focused Ion Beam (FIB) microscope for high-resolution ion beam imaging and site-specific TEM specimen preparation have been well documented [2-4]. However, the currently available TEM sample preparation techniques face significant challenge when dealing with fine powders. Part of the difficulty is that the powder cannot be loaded directly into the microscope for in-situ lift-out and FIB sectioning for ex-situ lift-out process. Using the "direct lift-out" technique, the author was able to prepare TEM specimens directly from very large specimens [5]. However, making TEM specimen from such small specimens is still a challenge. Early work by Cairney and Munroe [6] demonstrated a method to prepare TEM specimens from fine FeAl and WC powders. In their experiment, powders were first embedded in a low-viscosity epoxy resin, and then followed by a traditional lift-out routine. However, such method is not only tedious, but also makes the powder surface in direct contact with epoxy. For thin surface films, this will make TEM microanalysis nearly impossible.

In this study, an individual particle was attached to the edge of the TEM grid (Figure 1) using a conventional ex-situ lift-out tool. It was then thinned using the conventional FIB-TEM specimen preparation routine [5]. This TEM sample preparation routine can be used to prepare TEM specimens from very small particles. The sample can be directly mounted onto the TEM grid before loading into FIB for sectioning and imaging, and subsequent TEM sample preparation. A highresolution FIB image taken from FIB polished cross-section (Figure 2) showed a thin, but distinctive layer of surface film on the $\mathrm{Mg}$ particle.

The TEM specimen was further studied using a Philips CM20 FEG TEM. Preliminary TEM analysis as shown in Figure 3 indicated the surface film is very thin (on the order of $20 \mathrm{~nm}$ in this case), and is rich in oxygen according to both the EDS spectrum and EDS oxygen map. The weak oxygen X-ray signal is attributed to the relatively thin surface film. The exact nature of the surface film need to be further characterized using electron micro-diffraction in TEM, and will be reported elsewhere. 


\section{REFERENCES}

[1]. P. Burke, D. Fancelli. V. Laverdiere and G. J. Kipouros, "Investigation of the Sintering Fundamentals of Magnesium Powders", in print, CMQ, (2009).

[2]. Jian Li, Focused Ion Beam Microscope, Much More than an Ion Milling Machine, Journal of Metals, vol.58 No.3, 27-31, 2006.

[3]. Jian Li, M. Elboujdaini, Bingyan Fang, W. Revie and Michael W. Phaneuf, Microscopy Study of Intergranular Stress Corrosion Cracking of X-52 Line Pipe Steel, Corrosion, vol. 62 (No. 4), 316-322, 2006.

[4]. L.A. Giannuzzi and F.A. Stevie, Micron, 30, (issue 3) (1999) p.197.

[5]. Jian Li, T. Malis and S. Dionne, Recent Advances in FIB TEM Specimen Preparation Techniques, Journal of Materials Characterization, vol. 57, 64-70, 2006.

[6]. J.M. Cairney and P.R. Munroe, "Preparation of Transmission Electron Microscope Specimens from FeAl and WC Powders Using Focused-ion Beam Milling”, Materials Characterization, 46, (2001), 297-304.
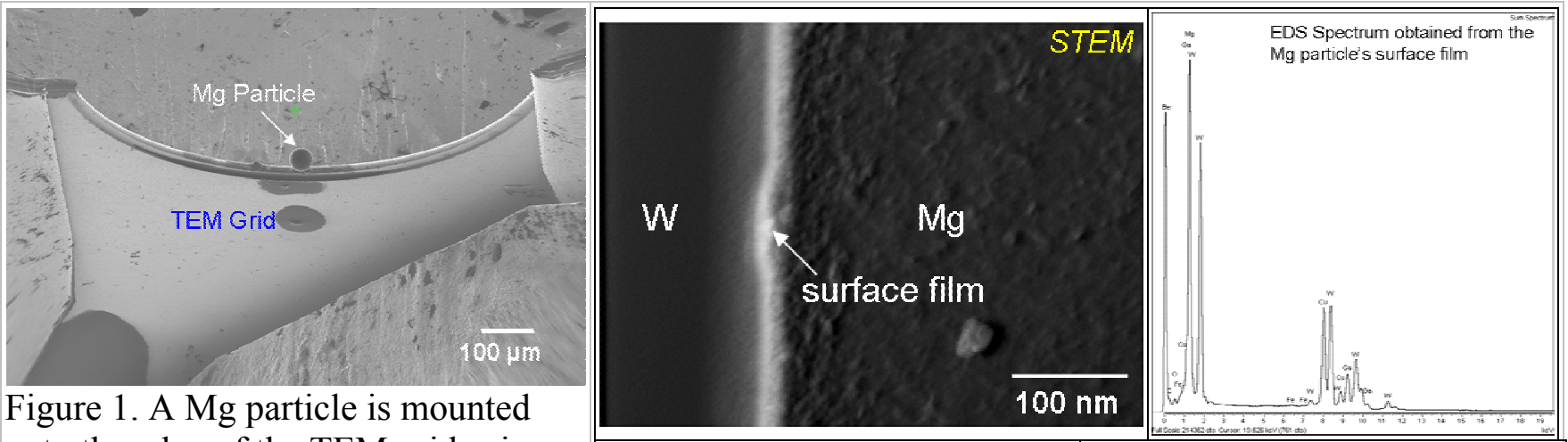

Figure 1. A Mg particle is mounted onto the edge of the TEM grid using an external lift-out tool

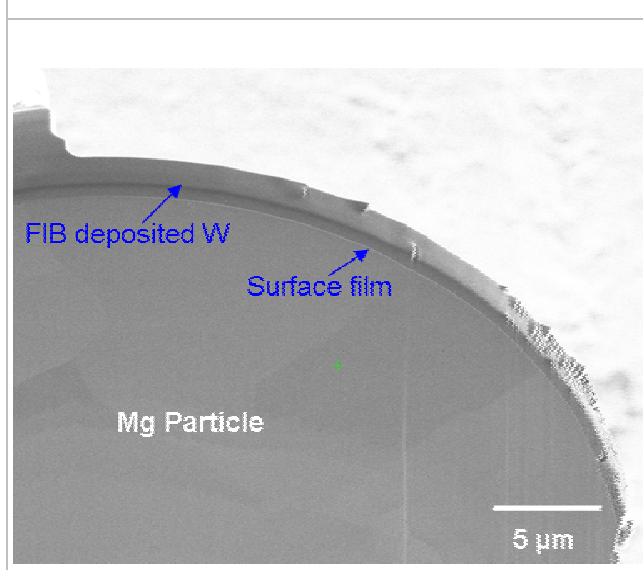

Figure 2. FIB secondary electron image showing the thin film formed on the Mg particle
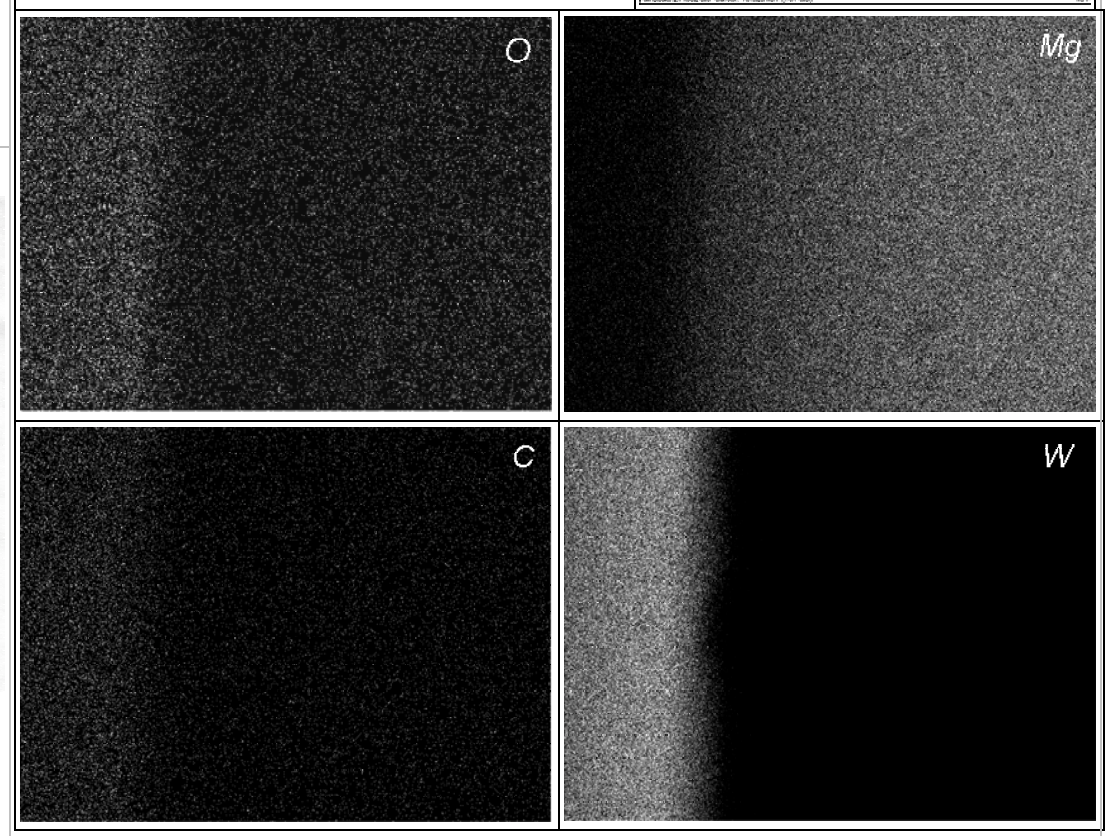

Figure 3. STEM image, corresponding EDS spectrum and maps 